\title{
Remote instruction and distance education: A response to Covid-19
}

\author{
J. Lindner ${ }^{1}$, C. Clemons ${ }^{2}$, A. Thoron ${ }^{3}$, N. Lindner ${ }^{4}$
}

\section{Abstract}

The purpose of the qualitative study was to explore how middle and secondary school agriscience teachers define remote instruction and distance education. This research was conducted as a response to the COVID-19 pandemic. Data for the study were collected during the time schools were closed and/or offering remote instruction. A purposive sample of seventeen agriscience education teachers in the States of Alabama and Georgia were selected for this qualitative study. Data were collected using a structured interview questionnaire and analyzed using constant comparisons. The conceptual framework of this study was developed using transactional distance theory and bound by strategic analysis. Findings showed that secondary agriscience education teachers did not collectively define remote instruction and distance education in the same manner. Some defined them similarly, and some noted specific differences in how the terms are defined and used. These teachers identified strengths and opportunities that should be exploited and weaknesses and threats that should be mitigated. Recommendations for training in appropriate use of distance education delivery strategies are provided. Recommendations for additional research into the impact on student learning are provided.

\section{Keywords}

Teaching remotely, strategic analysis, delivery methods, delivery strategies, distance education

1. James R. Lindner, Alumni Professor of Agriscience Education, Auburn University, 5058 Haley Center, Auburn University, AL 36849, jrl0039@auburn.edu; https://orcid.org/0000-0002-1448-3846

2. Christopher A. Clemons, Assistant Professor of Agriscience Education, , Auburn University, 5070 Haley Center, Auburn University, AL 36849, cac0132@auburn.edu; https://orcid.org/0000-0001-9879-0888

3. Andrew Thoron, Associate Professor in the Department of Agricultural Education, Abraham Baldwin Agricultural College, ABAC 8, 2802 Moore HWY Tifton, GA 31793, andrew.thoron@abac.edu; https://orcid.org/0000-0002-9905-3692

4. Nicholas J. Lindner, graduate student in the School of Veterinary Medicine and Biomedical Sciences, Texas A\&M University, 416 Pronghorn Loop, College Station, TX 77845, lindnenj@email.tamu.edu; https://orcid.org/0000-0002-7140-6820 


\section{Introduction and Problem Statement}

During January of 2020, the coronavirus (COVID-19) emerged in the United States (Centers for Disease Control and Prevention, CDC, n.d.). By March of 2020, the World Health Organization (WHO) declared COVID-19 a pandemic (WHO, 2020). During this time, middle and secondary schools either shut down or moved to remote instruction until the end of the semester. The words or term remote instruction was being used ubiquitously by Alabama and Georgia schools in response to the COVID-19 pandemic. Remote instruction can be defined two ways. Let us consider the following example announcement of a fictitious school. Rydell High School is moving immediately to remote instruction for the remainder of the semester. In this example remote is an adjective and instruction is a noun. Instruction, therefore, would be provided remotely. Remote is defined (Merriam-Webster, 2020a) as "acting, acted on, or controlled indirectly from a distance" (para. 1). Using this example, we could consider remote instruction a term (Merriam-Webster, 2020b) defined as "a word or expression that has an exact meaning in some uses or is limited to a subject or field" (para.1). As a term, remote instruction, is not welldefined in the literature.

In the context of this study we are operationally defining remote instruction as the physical separation of instructors and students during the teaching and learning process. The central attribute of remote instruction is the separation by space during instruction. Distance education is generally regarded as a pedagogical concept (Moore, 1997) that is not necessarily bound by space constraints. Moore (1997) noted distance education "is a concept describing the universe of teacher-learner relationships that exist when learners and instructors are separated by space and/or by time" (p. 22). Dooley et al. (2005) wrote, "distance education is the application of delivery strategies using a variety of delivery methods with learning who are constrained by time/space/lifestyle" (p. 80). These authors noted, "... that delivery methods do not matter, delivery strategies do" (p. 80). Because the terms defined remote instruction and distance education are defined differently a problem may exist when the terms are used synonymously. The synonymous use of the terms may create confusion by academicians transitioning to remote instruction and researchers studying the phenomena.

\section{Theoretical and Conceptual Framework}

The conceptual framework of this study was developed using an expanded model of Moore's (1989) transactional distance theory. This study was also bound by the strategic planning process of identifying strengths, weakness, opportunities, and threats (SWOT) (Cojocariu et al., 2013; Dooley \& Murphrey, 2001; Goodstein et al., 1993) of remote instruction and distance education to better understand the internal and external environments in which decisions are made. Engaging students in the educational environment is critical for student learning. Smith and Rayfield (2016) noted project-based learning through supervised agricultural experiences was a critical component of agriscience programs. Merrow (2003) wrote that engagement was the key to student learning while Moore (1989) noted that interaction between students, instructors, and content is vital for engagement. Hillman et al. (1994) expanded the model to 
include interactions with technology. Dooley et al. (2005) postulated that maximized learning, quality instruction, and learning satisfaction occurs at the intersection of these interactions.

According to Moore (1989) and Hillman et al. (1994), transactional distance, as a threat to student learning, could be overcome by maximizing interactions: learner to content, learner to instructor, learner to learner, and learner to technology. Dooley et al. (2005) postulated that the easiest of interactions to mitigate is learner to content follow by learner to technology. It is the social interaction between and among learners and instructors that presents the greatest challenge. An individual's personal competence and motivation to learn at a distance are also critical but often overlooked aspect of distance education.

In the case of COVID-19, K-12 students were forced into remoted instruction with no regard for their competence or motivation to be taught or learn remotely. Fletcher et al. (2007) highlighted that advanced distribution learning systems can facilitate learning for students studying remotely and physically separated from the instructor. Wei and Chou (2020) found that a learners' perceptions of self-efficacy in online learning environments effected their learning readiness. Learners with a high level of self-efficacy toward online learning performed better than those with low levels of self-efficacy. Schoor and Bannert (2011) noted that online learners might not be as motivated to complete a learning activity as face-to-face learners.

The use of the term remote instruction is not well-documented in the literature. According to research and instruction librarian T. Shipman (personal communication March 25, 2020) "the term [remote instruction] has been close to impossible to find in the current context." One example (Maly, et al., 1998) refered to remote instruction as a tool for delivering instruction to learners enrolled in courses located in different places. Geyer and Effelsberg (1998) describe remote instruction as requiring synchronous interactions. The notion of distance education as a delivery strategy was not addressed in either of these articles. Hodges et al. (2020) articulated that understanding the difference between remote teaching and distance education was necessary to appropriate plan and delivery online learning experiences.

SWOT analysis related to remote instruction and distance education may help decision makers plan better beyond the immediate impact of remote instruction during COVID-19. Identifying and exploring internal strengths and weakness and external opportunities and threats of remote instruction and/or distance education may be key to addressing critical issues such administrative support, training, and incentives (Dooley \& Murphrey, 2001).

The educational reality of COVID-19 was middle and secondary school agriscience teachers went from preparing instructional lessons, supervising agricultural experiences, and preparing for spring events in a strictly face-to-face setting, to coping with mandates of school closings and calls for remote instruction with no face-to-face interaction allowed. Regardless of teacher competence or means to provide remote instruction or understanding of remote instruction, the shift was sudden and required.

Emerging research suggests that Cooperative Extension was capable of responding to the need to transform rapidly to online education (Narine \& Meier, 2020). Understanding how 
agriscience education teachers respond to immediate transition to remote instruction may better prepare schools for future disruptions to face-to-face learning.

\section{Purpose}

The purpose of this qualitative study was to explore how middle and secondary school agriscience teachers define remote instruction and distance education. The study sought further to explore SWOT of remote instruction and distance education in the context of the COVID-19 pandemic. The researchers were particularly interested to find if teachers differentiated between the term remote instruction and distance education. Two research questions guided this study: (a) how did middle and secondary school agriscience teachers operationalize the term remote instruction and distance education, and (b)what were middle and secondary school agriscience teachers' perceptions of remote instruction and distance education's SWOT?

\section{Methods}

This research was conducted as a rapid response to COVID-19 and offers a glimpse into the reality teachers were making during the pandemic. Data collection began on March 26, 2020 and ended on April 21, 2020. Data for this research study were collected using an open-ended structured interview questionnaire described below (Merriam \& Tisdell, 2015). Strategies proposed by LaDonna, et al. (2018) to enhance rigor when using open-ended questionnaires for data collection were followed: (a) the sole focus was the open-ended questions; (b) questions were sharply focused on the phenomena of study; (c) data analysis focused on rigorous insights of participant responses.

Participants were asked to provide narrative responses via Qualtrics to questions and were provided unlimited space to do so. This facilitated timeliness of data collection and reduced subjectivity bias of researchers. Researcher subjectivity (Peshkin, 1988) was a concern in this study as the researchers were faculty members teaching courses using distance education and remote instruction and a graduate student participating in remoted instruction. Participants were able to review their responses to ensure accuracy and completeness. Data were analyzed using constant comparisons to identify themes and subthemes that emerged from the data (Corbin \& Strauss, 2015; Dooley, 2007). Data were reviewed by and reflected on by two of the researchers to develop themes and subthemes that emerged from the study. This reflective analysis process was iterative in nature to ensure congruence of themes and subthemes and contributes to the trustworthiness criteria.

The questionnaire consisting of conditional questions based on whether participants defined remote instruction and distance education differently. For those that did not discern a difference they were asked to define remote instruction/distance education as a single inclusive term. They were then asked to describe the strengths, weakness, opportunities, and threats associated with teaching middle and/or secondary agricultural education using remote 
instruction/distance education. For those that defined the terms differently, participants were asked to define each term. They were then asked to describe the strengths, weakness, opportunities, and threats associated with teaching secondary agricultural education using remote instruction and distance education. Both groups of participants were then asked several personal characteristic questions described above.

During this time, most schools were closed and/or offering remote instruction. A purposive sample of seventeen agriscience teachers was selected for this qualitative study. Teachers were purposively selected based on their divergent personal characteristics. Participants were selected based on geographic location, years of teaching experience, level of instruction (middle or secondary), and number of students in program. Participants were from Alabama and Georgia and were located geographically from the northern regions, central regions, and southern regions. Participants years of experience were characterized as those with less than one year of experience; 1-5 years of experience; 6-10 years of experience; $11-15$ years of experience; and 16-20 years of experience. Participants taught at the middle school level, the secondary level, or both middle and secondary levels. Participants indicated that the number of students in their program were characterized as: $0-100 ; 101-200 ; 201-300$; or 301-400. No attempts were made to characterize findings based on the divergent characteristics or to generalize findings beyond study participants.

\section{Findings}

Three teachers (T14, T02, T03) were not currently teaching middle or secondary school agriscience curricula using remote instruction or distance education. These teachers also did not discern the difference between remote instruction and distance education. Nine teachers (T10, T04, T06, T16, T11, T12, T09, T17, and T18) were currently teaching middle or secondary school agriscience curricula using remote instruction or distance education. These teachers also did not discern the difference between remote instruction and distance education. An additional five teachers (T05, T07, T08, T13, and T15) were currently teaching middle or secondary school agriscience curricula using remote instruction or distance education. These teachers discerned the difference between remote instruction and distance education. Several themes emerged from the data: perceptions of remote instruction and distance education; internal factors; and external factors.

\section{Perceptions of Remote Instruction and Distance Education}

Teachers, overall, did not agree on whether remote instruction and distance education were synonymous. Teachers who did not discern a difference between the two were more likely to associate remote instruction and distance education using the term online. In an attempt to provide clarity of findings, themes that emerged from teachers who defined remote instruction and distance education the same are referred to as remote instruction/distance education respondents (RIDE); whereas themes that emerged from teachers who discerned a difference between the two modes of instruction are referred to as remote instruction respondent (RI) or distance education respondent (DE), respectively. 
Examples of how these teachers defined remote instruction and distance education included: "continuing to educate from an alternative location than usual, and primarily online" [TO4]; "online learning opportunities, assignments, and assessments" [T16]; "using online resources to instruct students" [T09]; and "continuing educating students as normal as possible, without face-to-face instruction, using online resources and tools" [T18].

Teachers who discerned a difference between the two noted that remote instruction tended to be defined primarily as the physical separation of instructor and student. Examples of how these teachers defined remote instruction included: "when your [sic] trying to conduct an in person class remotely" [T13]; "remote instruction would be live Zoom lectures" [T05]; and "distance education is learning for a student who may not always be present in the classroom setting" [T07]. Teachers defined distance education to include both physical separation of teacher and students as well as separation in time. Examples of how teachers defined distance education included: "when a lecturer has provided prerecorded lectures and materials for the individual to teach themselves" [T05]; and "virtual learning" [T07].

\section{Internal Factors}

Strengths and weaknesses were internal factors that schools and teachers had direct control over to exploit or minimize. Some trends emerged with respect to teachers' perceptions of internal strengths and weaknesses with respect to how they defined remote instruction and distance education. Teachers who did not discern a difference between the two tended to focus simply on continuation of instruction.

\section{RIDE Strength}

Strengths included students' ability to practice and guide their own instruction. "Many students already have an SAE [supervised agricultural experience] project to work on at home, and they can practice the skills they have already learned in the [AGED] program" [T16]. "Students have the ability to work at their own pace or own clock" [T06]. Teachers generally reported that remote instruction or distance education was better than nothing. Some teachers; however, indicated that there were no strengths associated with this type of education. "None that I can see at this point" [T09].

\section{RIDE Weakness}

Critical internal weaknesses that emerged included technological limitations, and a lack of hands-on learning activities. Internet access was partially restrictive, as lack of internet access was a genuine concern. "Many of my students do not have internet, and neither did I at first. This style of teaching has also taken away from the face-to-face explanations and stories that paper just can't portray" [T04]. "Students will miss out on the hands-on learning opportunities in the shop/lab setting...These are very hard to replicate remotely" [T16]. "No hands-on learning...Lack of internet access or slow speed" [T09]. 


\section{RI Strength}

Teachers provided different views of internal strengths and weakness when they defined remote instruction and distance education differently. These teachers noted that strengths of remote instruction centered on live instruction and provided teachers greater opportunities to use online resources to support instruction. "Remote [instruction] is done in place of regular instruction" [T15]. Strengths of remote instruction included: "access to more visual resources" [T07]; "the use of a video to demonstrate the inside workings of a piece of equipment" [T08]; and "provid[ing] students the opportunity to learn...different topics of agriculture" [T05].

\section{RI Weakness}

Weaknesses focused on lack of face-to-face interaction between teachers and students. "This transition is very stressful on everyone and I do not feel that taking their time to have them sit through lecture will be beneficial. The students are missing the opportunity to learn hands on skills" [T05]. "Lack of immediacy as compared to a face-to-face classroom environment" [T07] was a weakness. "Trying to ensure the students truly comprehend the material when you cannot give a traditional grade" [T13] was another weakness.

\section{DE Strength}

Strengths of distance education were concentrated around the ability of students to self-pace instruction and tailor learning to their educational needs. "[D]istance education provides students with the ability to work at their own pace when it is convenient for them. Preprovided materials allowed students that may not have internet at home to go to a hot spot, download what they needed and returned home to complete their work" [T05]. "[Distance education allows] for virtual learning through video classrooms where more immediacy is prevalent than remote education through virtual interactions" [T07].

\section{DE Weakness}

Weakness of distance education tended to focus on students' ability to manage their time wisely and work independently. "Distance education requires that the students work on their own and submit work in a timely manner" [T05]. Weaknesses of distance education included: "time constraints, scheduling, [and] technology access" [T07]; and "face to face interaction is lacking" [T13].

\section{External Factors}

Opportunities and threats pressure schools and teachers to respond to a given situation. Some trends emerged with respect to teachers' perceptions of opportunities and threats with respect to how they defined remote instruction and distance education. Teachers who did not discern a difference between the two tended to focus on opportunities for engagement with content meaningful to the individual student. They also focused on the threat of being able to authenticate learning.

\section{RIDE Opportunities}

Participants reported that opportunities that could be exploited included engaging students in meaningful learning opportunities. "I think we have had the opportunity to give our students 
assignments we normally would not have time for; "Things [sic] that let them explore and create their own projects, tests their skills and limits" [T04]. "This possibly offers the opportunities for students to feel more comfortable as they are able to learn in their home setting" [T06]. "[S]tudents still have the opportunity to do to learn [sic] or practice the skills they have learned in the program" [T16]. According to some teachers [T18 \& T17], however, opportunities for meaningful learning were minimal without direct face-to-face interactions with students.

\section{RIDE Threats}

Participants reported that threats that should be mitigated included student safety and security, teacher relationships, and authentication of learning. "A main concern about a 'threat' for my students, and all students really, is lack of a positive environment at home" [T04]. "Student safety must be considered" [T16]. "Cheating is a huge threat and most high school level test questions and answers can be located by a simple google search this greatly threatens the likelihood that students will be learning any material at all" [T06]. "The relationships between the students and teachers along with parent and industry support" [T09].

\section{RI Opportunities}

Participants reported that opportunities to support time management skills of students should be exploited. "Students are given the opportunity to learn how to be independent and manage their time own their own" [T05]. "[RI provides a] chance to expand on material through more open discussions" [T07].

\section{RI Threats}

Participants reported that threats focused on reaching student-to-instructor engagement and student-to-technology engagement. A major concern was students with IEPs or are ELLs that need additional help. "Also, many students face poverty and do not have internet access at home" [T05]. "I feel there isn't enough monitoring done or available for testing" [T08]. Authentication was also a concern here as described in previous sections.

\section{DE Opportunities}

Participants reported that opportunities to support individual progress/self-direction should be exploited. Distance education may be a great opportunity for those students that feel other classmates cause the class to fall behind. "Distance education provides those students that want to excel the ability to do so in a timely manner" [T05]. "[DE provides for ability to] work at one's own pace" [T07].

\section{DE Threats}

Threats focused primarily on the lack of skill development through experimental learning opportunities. Distance education does not provide opportunities for follow-through by students. 


\section{Conclusions, Discussion, and Recommendations}

The findings presented a nuanced snapshot of how teachers operationalize the terms remote instruction and distance education. It was interesting to note Alabama and Georgia schools ubiquitous use of the term remote instruction (a term rarely used in the literature before COVID-19 [T. Shipmam, personal communication, March 25, 2020]) instead of the term distance education (a term well established in the literature [Moore, 1997]). This implies that those calling for remote instruction discerned the distinction between remote instruction as simply the separation of teachers and students by space for the purpose of continued instruction without regard to appropriate use of delivery strategies.

Findings showed that some teachers differentiated in their definitions of distance education and remoted instruction and some teachers did not (RIDE). RIDE teachers who did not define the terms differently tended to support the notion that remote instruction and distance education was merely a delivery method. Teachers who did define the terms differently tended to support the notion that distance education was a delivery strategy and that remote instruction was primarily the physical separation of instructor and student. This implies that while teachers can provide instruction remotely, lack of teacher competence in distance education as a delivery strategy may negatively impact student learning, quality of instruction, and learner satisfaction. This was consistent with what Dooley et al. (2005) postulated.

The mechanics (or at least the optics) of providing instruction remotely are much easier and visible than ensuring teachers are properly trained to provide quality distance education. For example, recording a lecture for remote synchronous or asynchronous viewing and delivering the lecture via an internet-connected video conferencing service like Zoom, Skype, Canvas, etc., may constitute remote instruction, but it does not necessarily address relationships (as described by Moore, 1989) and delivery strategies associated with distance education. While the use of video instruction can certainly be a part of distance education, methods for insuring interaction and engagement among students, instructors, content, and technology are what ensures distance education maximizes learning, quality, and satisfaction.

Recommendation for practice includes expanded training of teachers in appropriate delivery strategies for remote instruction. Recommendations for research include studying: how teachers attempted to use appropriate distance education delivery strategies during the COVID-19 pandemic; and student learning, quality of instruction, and learner satisfaction during the COVID-19 pandemic.

Agriscience teachers' perceptions of SWOTs associated with remote instruction and distance education differed based on how they defined those terms. Teachers noted that, given the hands-on nature of agriscience education, neither remote instruction nor distance education was ideal. Teachers' positive perceptions of strengths of distance education and/or remote instruction should be exploited to ensure continued instruction during COVID-19. These strengths included: guided instruction; individualized instruction; self-pace learning; skill 
practice; and availability online resources. Teachers' negative perceptions of the weaknesses of distance education and/or remote instruction should be mitigated. These weaknesses included: lack of internet access; lack of hands-on activities; lack of face-to-face interactions; time management; and lack of tools to insure comprehension.

Teachers were optimistic that that distance education and/or remote instruction could engage students in meaningful learning opportunities. These opportunities may allow students the time and space to explore agriscience education content that might not normally be presented in a traditional face-to-face course. Opportunities also focused on allowing accelerated learning for advanced students. Teachers were concerned how to mitigate threats associated with: cheating; skill development; student safety and securing; and lack of student-to-instructor and technology engagement.

The challenges wrought by the events of the spring 2020 semester were unprecedented and generally teachers were ill-prepared to transition to online education. It appears that few were prepared to use distance education delivery strategies for providing instruction remotely. The initial hurdle teachers had to address was a physical separation between themselves and students. The next hurdle of training teachers to use appropriate delivery strategies lie ahead. Our findings are inconsistent with Hodges et al. (2020) whom articulated a difference between remote instruction and distance education. More participants did not indicate a difference between remote instruction and distance education than indicated a difference.

Additional research and evaluation are needed to understand better the impacts of remote instruction on student learning. An understanding of SWOTs associated with remote instruction, coupled with additional training, has potential to help agriscience education teachers better plan and delivery instruction while meeting student learning needs if future events arise that require remote instruction.

\section{References}

Cojocariu, V. M., Lazar, I., Nedeff, V., \& Lazar, G. (2014). SWOT analysis of e-learning educational services from the perspective of their beneficiaries. Procedia-Social and Behavioral Sciences, 116(0), 1999-2003. https://doi.org/10.1016/i.sbspro.2014.01.510

Centers for Disease Control and Prevention. (n.d.). https://www.cdc.gov/coronavirus/2019$\underline{\mathrm{nCoV} / \text { index.html }}$

Corbin, J., \& Strauss, A. (2014). Basics of qualitative research: Techniques and procedures for developing grounded theory. Sage Publications.

Dooley, K. E. (2007). Viewing agricultural education research through a qualitative lens. Journal of Agricultural Educations, 48(4), 32-42. https://doi.org/10.5032/jae.2007.04032 
Dooley, K. E., Lindner, J. R., \& Dooley, L. M. (2005). Advanced methods in distance education: Applications and practices for educators, administrators and learners. IGI Global.

Dooley, K. E., \& Murphrey, T. P. (2001, April 4-7). Administrator, faculty, and support staff perceptions of distance education technologies. In Association for International Agricultural and Extension Education (AIAEE), 2001 Proceedings of the 17th Annual Conference. https://www.aiaee.org/attachments/article/1391/pa14.pdf

Fletcher, J. D., Tobias, S., \& Wisher, R. A. (2007). Learning anytime, anywhere: Advanced distributed learning and the changing face of education. Educational Researcher, 36(2), 96-102. https://doi.org/10.3102/0013189X07300034

Geyer, W., \& Effelsberg, W. (1998). The digital lecture board: A teaching and learning tool for remote instruction in higher education. In T. Ottmann \& I. Tomek (Eds.), Proceedings of ED-MEDIA 1998: World Conference on Educational Multimedia, Hypermedia \& Telecommunications. 63-69. Association for the Advancement of Computing in Education (AACE). https://www.learntechlib.org/primary/p/24273

Goodstein, L., T. Nolan, and J. W. Pfeiffer. (1993). Applied strategic planning: How to develop a plan that really works. McGraw-Hill.

Hillman, D. C., Willis, D. J., \& Gunawardena, C. N. (1994). Learner-interface interaction in distance education: An extension of contemporary models and strategies for practitioners. American Journal of Distance Education, 8(2), 30-42.

Hodges, C., Moore, S., Lockee, B., Trust, T., \& Bond, A. (2020, March 27). The difference between emergency remote teaching and online learning. EDUCAUSE Review. https://er.educause.edu/articles/2020/3/the-difference-between-emergency-remoteteaching-and-online-learning

LaDonna, K. A., Taylor, T., \& Lingard, L. (2018). Why open-ended survey questions are unlikely to support rigorous qualitative insights. Academic Medicine, 93(3), 347-349. https://doi.org/10.1097/ACM.0000000000002088

Maly, K., Overstreet, C. M., González, A., Denbar, M. L., Cutaran, R., \& Karunaratne, N. (1998). Automated content synthesis for interactive remote instruction. https://files.eric.ed.gov/fulltext/ED428695.pdf

Merriam, S. B., \& Tisdell, E. J. (2015). Qualitative research: A guide to design and implementation. John Wiley \& Sons.

Merriam-Webster. (n.d.-a). Merriam-Webster.com dictionary. Retrieved March 25, 2020, from https://www.merriam-webster.com/dictionary/remote 
Merriam-Webster. (n.d.-b). Merriam-Webster.com dictionary. Retrieved March 25, 2020, from https://www.merriam-webster.com/dictionary/term

Merrow, J. (2003, February 5). Easy grading makes "deep learning” more important. USA Today, $12 \mathrm{~A}$.

Moore, M.G. (1997). Theory of transactional distance. In D. Keegan (Ed.), Theoretical principles of distance education. 22-38. Routledge.

Moore, M. G. (1989). Three types of interaction. Taylor \& Francis.

Narine, L., \& Meier, C. (2020). Responding in a time of crisis: Assessing extension efforts during COVID-19. Advancements in Agricultural Development, 1(2), 12-23. https://doi.org/10.37433/aad.v1i2.35

Peshkin, A. (1988). In search of subjectivity-One's own. Educational Researcher, 17(7), 17-21. https://doi.org/10.3102/0013189X017007017

Schoor, C., \& Bannert, M. (2011). Motivation in a computer-supported collaborative learning scenario and its impact on learning activities and knowledge acquisition. Learning and Instruction, 21(4), 560-573. https://doi.org/10.1016/i.learninstruc.2010.11.002

Smith, K. L., \& Rayfield, J. (2016). An early historical examination of the educational intent of supervised agricultural experiences (saes) and project-based learning in agricultural education. Journal of Agricultural Education, 57(2), 146-160. https://doi:10.5032/jae.2016.02146

Wei, H-C. \& Chou, C. (2020). Online learning performance and satisfaction: do perceptions and readiness matter? Distance Education, 41, 1, 48-69. https://doi.org/10.1080/01587919.2020.1724768

(C) 2020 by authors. This article is an open access article distributed under the terms and conditions of the Creative Commons Attribution license (http://creativecommons.org/licenses/by/4.0/). 